\title{
Mothers' willingness to accept and pay for vaccines to their children in western Iran: a contingent valuation study
}

\author{
Satar Rezaei ${ }^{1}$, Abraha Woldemichael ${ }^{2}$, Masoumeh Mirzaei ${ }^{3}$, Shima Mohammadi ${ }^{3}$ and Behzad Karami Matin ${ }^{1 *}$
}

\begin{abstract}
Background: The clients' willingness to accept (WTA) and willingness to pay (WTP) for a given good or service can help elicit the monetary value of that good or service. This study aims to assess the WTA and WTP of mothers attending primary health centers for vaccines to their children during 2019 in Kermanshah city, western Iran.

Methods: We conducted a cross-sectional study on a total of 667 mothers attending primary health centers for vaccines to their children aged two to 18 months. A multistage sampling technique was employed to involve the mothers in the study, and data were collected using a self-administrated open-ended questionnaire. The multivariate linear regression model was used to identify the factors associated with the mothers' WTP and WTA for vaccines to their children.

Results: The study indicated that 94.2 and $93.1 \%$ of the mothers respectively had WTA and WTP values greater than zero, with their corresponding mean values of US\$ 6.8 and US\$ 4.4. The mothers in the higher monthly household income category, mothers born in the urban areas, and being a female child showed statistically significant positive associations with the mothers' WTA for the vaccines. While there was a statistically significant positive relationship between monthly household income and the mothers' WTP; a statistically significant negative relationship exists between the mothers' age and their WTP for the vaccine to their children.

Conclusions: The findings indicated the mothers' WTA to WTP ratio of greater than one for the vaccines to their children. The most important factor associated with the mothers' WTA and WTP was the monthly household income. Thus, improving the socio-economic standards of women in the study area might contribute to reinforcing their immunization services seeking behavior to their children.
\end{abstract}

Keywords: Willingness to pay, Willingness to accept, Contingent valuation, Childhood vaccination

\section{Background}

Determining the monetary value of given healthcare services such as vaccinations and their distributions as healthcare resources create challenges to health policymakers in many health systems, especially to those in the under-resourced countries [1]. Besides, assigning the

\footnotetext{
*Correspondence: bkmatin1344@gmail.com

${ }^{1}$ Research Center for Environmental Determinants of Health, Health Institute, Kermanshah University of Medical Sciences, Kermanshah, Iran

Full list of author information is available at the end of the article
}

monetary value of public goods or services is highly complicated because they are devoid of a formal market [2]. However, there existed several methods, including the contingent valuation $(\mathrm{CV})$ method, for eliciting the monetary value of nonmarket goods and services [3-5]. The $\mathrm{CV}$ is a direct method of eliciting the monetary value of public goods or services by means of surveys and employing the willingness-to-pay (WTP), which indicates the participants' maximum amount of money they are willing to give up to obtain the good or service

C C The Author(s). 2020 Open Access This article is licensed under a Creative Commons Attribution 4.0 International License, which permits use, sharing, adaptation, distribution and reproduction in any medium or format, as long as you give appropriate credit to the original author(s) and the source, provide a link to the Creative Commons licence, and indicate if changes were made. The images or other third party material in this article are included in the article's Creative Commons licence, unless indicated otherwise in a credit line to the material. If material is not included in the article's Creative Commons licence and your intended use is not permitted by statutory regulation or exceeds the permitted use, you will need to obtain permission directly from the copyright holder. To view a copy of this licence, visit http://creativecommons.org/licenses/by/4.0/ The Creative Commons Public Domain Dedication waiver (http://creativecommons.org/publicdomain/zero/1.0/) applies to the data made available in this article, unless otherwise stated in a credit line to the data. 
or the willing to accept (WTA), the minimum amount of money that an individual can increase to obtain the attribute $[4,6,7]$. The WTA and WTP measures are also helpful to assess the within-subject disparity on a given attribute [8].

The amount that a person is willing to accept or pay is a rationale decision and is crucial to cost-benefit analysis. However, the WTA is usually considerably higher than the WTP, and this disparity exists even when we use different elicitation methods [6]. The disparity between the WTA and WTP is a well-established measure in behavioral economics or welfare economics $[9,10]$ and is replicable, universal, and persistently occurring even in participants that have an understanding of the elicitation procedure [11]. Several factors, including the complex psychological processes such as the participants' attitudes, feelings, familiarity with the target good, risk attitudes, and personality [12] as well as the emotions, and moral perceptions of individuals attached to the attribute [13] contribute to the occurrence of the disparity. The higher value individuals attach to objects they own (WTA) than to objects they do not (WTP) is another source of the disparity [9]. Moreover, people dislike losses more than they value the corresponding gains [14]. The behaviors of individuals, such as loss aversion, that affect the WTP can increase the gap. For substitute goods, the WTA to WTP ratio is smaller, while for health or safety and public or non-market goods, it remains the highest [15]. However, the gap can be turned on and off and can be a source of problematic interpretation [16].

The hypothetical, real, and random real valuation questions can elicit the persons' WTA and WTP [6]. The values of different attributes, including time, can be generated using either of these approaches [10]. Our study applied the hypothetical valuation method to elicit mothers' WTA and WTP for vaccines to their children because evidence shows an insignificant difference between the ratios obtained by the real experiments and hypothetical experiments [6]. Besides, the fact that the mothers had fairly equal familiarity with the immunization service and lower misconceptions or misunderstanding about the vaccines contributes to the production of a narrower disparity between the valuations $[16,17]$.

The government of Iran has introduced the expanded program on immunization (EPI) for children against targeted vaccine-preventable diseases in 1984. Thus, the mothers have the right for their children to freely get the EPI service as it is a public good. Such attributes are best valued using the WTA questions [14]. Accordingly, the child immunization services have been provided by the public health sector free of charge at the health centers of both the urban and rural settings of Iran. Besides, the introduction of the health sector evolution plan in
May 2014, resulted in the outsourcing of some of the health centers and provision of the EPI services freely by the private health centers. Currently, the routine EPI targeted ten vaccine-preventable diseases including the provision of the bacillus Calmette-Guerin (BCG) [at birth], oral poliovirus vaccine (OPV) [at birth, 2, 4, 6, 18 months and 6 years of age], hepatitis B (HepB) [at birth, 2 and 6 months], diphtheria, tetanus and pertussis (DTP) [at 6 year of age], pentavalent (DTP + HepB + Haemophilus influenzae type b (Hib)) [at 2, 4 and 6 months], and measles-mumps-rubella (MMR) [at 12 and 18 months age] [18]. Additional file 1: Appendix 1 is a summary of the current immunization program in Iran.

The poor economic performance of Iran, especially in recent years due to the sanction plus the limited available public primary health care units to providing EPI services, negatively affected healthcare service provision and use by citizens. Eliciting the WTA and WTP of people for a given good or service in under-resourced countries like Iran can better inform policy-makers not only the monetary value of the good or service but also illuminate the understanding associated with health sector reform such as the immunization service provider shift from public to private. The public goods valuation using the WTA and WTP in the health sector is very rare. Besides, despite our search for different sources, we could not get evidence showing clients' WTA and WTP for an attribute in Iran. Our study aims to elicit mothers' WTA and WTP for vaccines to their children in Kermanshah city, western Iran. The findings contribute paramount importance in increasing the knowledge base on WTA and WTA in healthcare in the context and to policy decisions to strengthen the expansion EPI service provision in the private health sectors in Iran and perhaps serve as input in other contexts with similar conditions.

\section{Methods \\ Study setting}

We conducted the study in Kermanshah city, a metropolitan and capital city of Kermanshah province, located in western Iran. Iran's 2016 population census report indicated that the city had a total of $1,083,833$ people. Kermanshah city had 50 functional public health centers providing primary healthcare to people, including child immunization services.

\section{Study design, sample size and sampling method}

We conducted a cross-sectional study using the CV method on a total of 700 mothers attending selected health centers of Kermanshah city to elicit their WTA and WTP for vaccines to their 2-18 months old children using a convenience sampling technique. To involve the mothers in the study, we clustered the city into central, 
western, eastern, southern, and northern geographic areas, and evenly allocated the sample to each area $(n=$ 140). Then, after proportionately allocating the sample size of each area to three randomly selected health centers, we collected data from mothers attending the health centers using a self-administered questionnaire during September to December 2019.

\section{Data collection and variables}

The study involved two parts. The first part employed a self-administrated questionnaire to obtain data on sociodemographic characteristics, including the children's gender, mothers' age, and educational level, households' monthly income, and health insurance coverage. The second part of the study elicited the mothers' openended WTA and WTP values for vaccines to their children as recommended in other studies [19, 20]. With the understanding that the EPI service is free of charge, we involved the mothers in the study after getting their children immunized. We presented each mother two scenarios and asked open-ended questions to determine her WTA and WTP for the vaccines to her child. The WTA was elicited by asking the question: "Had your child not get the vaccines freely today, how much money would you have compensated for the vaccines appropriately?". Again, we elicited the WTP by posing the question: "Suppose the vaccines were not free of charge and you must pay directly because your child should not miss the vaccines. How much money could you have paid to get the vaccines?"

In this study, the mothers' WTA and WTP were the outcome variables, and the children's sex, mothers' age in years, birthplace and educational level, and households' monthly income (in US\$) as well as households' health insurance coverage status were the independent variables. We constructed the questionnaire based on the research objective, and two health economists and an epidemiologist checked for its content validity. Then, we conducted a pilot study on 30 participants in a health center in the study area after amending the opinions of the experts. Once the hypothetical scenarios and the questions were clear and ensured easily understood, we commenced our study.

\section{Statistical analysis}

We used descriptive statistics (percentages, mean with standard deviation (SD), and mean ratios) to characterize the mothers' WTA and WTP value for the routine EPI vaccines for their children. Besides, because both outcome variables (WTA and WTP) are continuous, we used a multiple linear regression model to assess the association between the dependent and independent variables. The mathematical expression of the model is as follows:

$$
\begin{aligned}
y= & \beta_{1}+\beta_{2} \text { age }+\beta_{2} \text { edu }_{i}+\beta_{3} \text { hi }_{i}+\beta_{5} \text { sex }_{i}+\beta_{6} \text { place }_{i} \\
& +\beta_{7} \text { income }_{i}+\mathcal{E}_{i}
\end{aligned}
$$

Where $\boldsymbol{y}$ is the outcome variable (WTA or WTP), age represents the mother's age, $\boldsymbol{e d u}$ is educational level of the mother, $\boldsymbol{h} \boldsymbol{i}$ is the household's health insurance coverage status, sex is the child's sex, place is the mother's place of residence, income is the monthly income of the household, and $\mathcal{E}$ is the residual.

First, we transformed the mothers' data with the unwillingness to accept and unwilling to pay values to zero and included in the analysis. Then, we tested the WTP and WTA values for the normality of the distributions of the residuals, and the findings of each model indicated the uneven distribution of the residuals. Then, we further performed a logarithmic transformation of the values and tested for multicollinearity of the variables in the models using the variance inflation factor (VIF). The mean VIF values for the two models (WTP $=1.47$ and $\mathrm{WTA}=1.45$ ) were less than 10, and we accepted the variables in the models for the analyses [21]. We used the robust for the standard error to minimize the heteroscedasticities.

Second, using the mentioned-above equation and the logarithmic transformed dependent variable, we applied the following log-linear regression model to explore the association between the mothers' WTP (WTA) and the explanatory variables.

The interpretation of the coefficients of the findings was different from the linear-linear model because the outcome variables were logarithmically transformed, and the explanatory variables were linear. For example, a coefficient of -0.198 for a variable $\mathrm{x}$ indicates that for every one-unit increase in $x$, the dependent variable increases by about $22 \%[(\exp (0.198)-1) * 100=21.9]$. We used the statistical software package Stata version 14.2 for analysis, and the findings were decided statistically significant at the $p$-value of less than 0.05 .

\section{Results}

Out of the total sample of 700 mothers, 667 of them had complete data for the analysis, making a response rate of $95.3 \%$. The mothers' age ranged from 15 to 50 years, with a mean age of 30.8 years and a standard deviation (SD) of 6.6 years. The households with health insurance coverage and mothers with an educational status less than high school accounted for 88.3, and 30\%, respectively. More than half of the mothers (52.3\%) reported having female children (Table 1).

Overall, 628 (94.2\%) mothers had the WTA values of greater than zero, while 39 (5.8\%) mothers had the WTA values of zero (holding that the monetary values could not compensate for the vaccines). Furthermore, 621 (93.1\%) mothers had the WTP values of greater than zero, and 46(6.9\%) mothers had zero values for the 
Table 1 Descriptive characteristics of participants included in the study

\begin{tabular}{|c|c|c|}
\hline Sociodemographic variables & $\mathrm{n} /$ mean & Percentage/SD \\
\hline Mother's mean age (in years) & 30.8 & 6.6 \\
\hline \multicolumn{3}{|l|}{ Mother's education level } \\
\hline Less than high school & 200 & 30.0 \\
\hline High school and higher & 467 & 70.0 \\
\hline \multicolumn{3}{|l|}{ Health insurance coverage } \\
\hline Yes & 589 & 88.3 \\
\hline No & 78 & 11.7 \\
\hline \multicolumn{3}{|l|}{ Sex of child } \\
\hline Female & 349 & 52.3 \\
\hline Male & 318 & 47.7 \\
\hline \multicolumn{3}{|l|}{ Mother's birthplace } \\
\hline Rural & 118 & 17.7 \\
\hline Urban & 549 & 82.3 \\
\hline \multicolumn{3}{|c|}{ Monthly household income (US\$) } \\
\hline$<80$ & 105 & 15.7 \\
\hline $80-160$ & 297 & 44.5 \\
\hline $160-320$ & 211 & 31.6 \\
\hline$>320$ & 54 & 8.10 \\
\hline
\end{tabular}

Note: At the time of this study, US\$1 was equal to 125,000 Iranian Rilas (IRR)

reason of "I could not afford the price" in 20(43.5\%) and "the vaccines should be free of charge" in the rest 25(56.5\%) of mothers]. Generally, 23 (3.4\%) mothers had zero value for both the WTA and WTP. The mothers with zero values of the WTP, WTA, and both WTP and WTA accounted for 46(6.9\%), 39 (5.8\%), and $23(3.4 \%)$, respectively. Overall, 621 (93.1\%) mothers had the WTP for the vaccines with values greater than zero, while $46(6.9 \%)$ had the WTP values of zero [consisting of 20 (43.5\%) mothers with the reasons of "I cannot afford", which revealed the true zero WTP value, and another 25(56.5\%) mothers that hold "the vaccines should be free of charge", hence, a protested WTP values of zero]. The mean (SD) WTA and WTP values of the mothers for the vaccines accounted for US\$ 6.8 (12.6), and US\$ 4.3 (9.7), respectively (Table 2). The mean difference between the WTA and WTP values revealed a 36.8\% higher WTA value than the WTP value, and the mean WTA to WTP ratio was about 1.6. The mean (SD) WTA and WTP values for mothers in the monthly household income category of less than US\$ 80 were 5.2 (10.1) US\$ 2.4 (4.6), while their corresponding values for those in the monthly income category of more than US\$ 320 were US\$ 12.4 (14.1), and US\$ 8.1(12.7), respectively.

The mothers in the higher monthly household income category, mothers born in the urban areas, and being a female child showed statistically significant positive associations with the logarithm of the mothers' WTA for the
Table 2 The average of WTA and WTP regarding to sociodemographic variables of the samples

\begin{tabular}{|c|c|c|}
\hline Explanatory variables & $\begin{array}{l}\text { Mean WTA (SD) in US\$ } \\
(n=667)\end{array}$ & $\begin{array}{l}\text { Mean WTP (SD) in US\$ } \\
(n=667)\end{array}$ \\
\hline Mother's age (in year) & $6.8(12.6)$ & $4.3(9.7)$ \\
\hline \multicolumn{3}{|c|}{ Mother's educational level } \\
\hline Below high school & $6.2(12.5)$ & $3.4(8.8)$ \\
\hline $\begin{array}{l}\text { High school and } \\
\text { above }\end{array}$ & $7.1(12.7)$ & $4.7(10.1)$ \\
\hline \multicolumn{3}{|c|}{ Health insurance coverage } \\
\hline Yes & $6.8(12.8)$ & $4.4(9.7)$ \\
\hline No & $6.2(11.3)$ & $4.0(10.0)$ \\
\hline \multicolumn{3}{|l|}{ Sex of the child } \\
\hline Female & $7.2(12.6)$ & $4.7(10.6)$ \\
\hline Male & $6.3(12.6)$ & $3.9(8.6)$ \\
\hline \multicolumn{3}{|l|}{ Mother's birthplace } \\
\hline Rural & $7.5(14.2)$ & $3.9(8.7)$ \\
\hline Urban & $6.6(12.3)$ & $4.4(9.9)$ \\
\hline \multicolumn{3}{|c|}{ Monthly household income (US\$) } \\
\hline$<80$ & $5.2(10.1)$ & $2.4(4.6)$ \\
\hline $80-160$ & $6.3(12.7)$ & $4.5(10.9)$ \\
\hline $160-320$ & $6.8(13.0)$ & $4.1(8.6)$ \\
\hline$>320$ & $12.4(14.1)$ & $8.1(12.7)$ \\
\hline
\end{tabular}

WTA willingness to accept, WTP willingness to pay, SD standard deviation, IRR Iranian Rials. Note: At the time of this study, US\$1 was equal to 125,000 IRR

vaccines (Table 3). Holding all other variables constant, the WTA was $300.6 \% \quad$ ([3.006 = exp.(1.388)$1]^{* 100)}$ higher for the mothers in the monthly household income category of more than US\$ 320 than those in the income category of less than US\$ 80 . The mothers' age, and the households' health insurance coverage did not show any statistically significant association with the mothers' WTA for the vaccine.

Table 4 presents the relationship between the logarithm of the WTP and the explanatory variables included in the regression model. There was a statistically significant negative relationship between the mothers' age and their WTP for the vaccine to their children. That is, after adjusting for the explanatory variables, the mothers' WTP for the vaccines decreased by about $1.33 \%\left([-0.0133=\exp .(-0.0134)-1]^{*} 100\right)$ as the mothers' age increased with each additional year. Besides, there was a statistically significant positive relationship between monthly household income and the mothers' WTP. The WTP was $200.8 \%$ ([2.008=exp.(1.1013)$\left.1]^{*} 100\right)$ higher for the mothers in the monthly household income category of more than US\$ 320 than those in the income category of less than US\$ 80. The WTP did not show any statistically significant association with the 
Table 3 Ordinary least square regression of the logarithm of WTA of mothers to vaccinate their children $(n=667)$

\begin{tabular}{|c|c|c|c|c|}
\hline Log WTP & Coefficient & Robust S.E & $p$-value & $95 \% \mathrm{Cl}$ \\
\hline Mothers' age (in year) & -0.0010 & 0.0084 & 0.901 & -0.0176 to 0.0155 \\
\hline \multicolumn{5}{|l|}{ Mother's education level } \\
\hline \multicolumn{5}{|l|}{ Below high school (ref.) } \\
\hline High school and above & 0.083 & 0.1337 & 0.533 & -0.1792 to 0.3462 \\
\hline \multicolumn{5}{|l|}{ Health insurance coverage } \\
\hline \multicolumn{5}{|l|}{ Yes (ref.) } \\
\hline No & 0.150 & 0.1736 & 0.388 & -0.1909 to 0.4909 \\
\hline \multicolumn{5}{|l|}{ Sex of the child } \\
\hline \multicolumn{5}{|l|}{ Female (ref.) } \\
\hline Male & $-0.2823^{a}$ & 0.1093 & 0.010 & -0.4970 to -0.0676 \\
\hline \multicolumn{5}{|l|}{ Mother's birthplace } \\
\hline \multicolumn{5}{|l|}{ Rural (ref.) } \\
\hline Urban & $0.3106^{\mathrm{a}}$ & 0.1556 & 0.046 & 0.0050 to 0.6163 \\
\hline \multicolumn{5}{|c|}{ Monthly household income (IRR) } \\
\hline \multicolumn{5}{|l|}{$<80$} \\
\hline $80-160$ & 0.2201 & 0.1612 & 0.173 & -0.0965 to 0.5366 \\
\hline $160-320$ & $0.3602^{\mathrm{a}}$ & 0.1793 & 0.045 & 0.0079 to 0.7125 \\
\hline$>320$ & $1.388^{\mathrm{a}}$ & 0.2509 & 0.001 & 0.8955 to 1.8810 \\
\hline
\end{tabular}

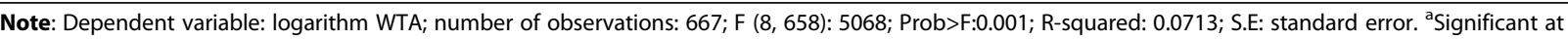
$5 \%$ level

Table 4 Multiple linear regression model of the logarithm of WTP of mothers to vaccinate their children $(n=667)$

\begin{tabular}{|c|c|c|c|c|}
\hline Log WTP & Coefficient & Robust S.E & $p$-value & $95 \% \mathrm{Cl}$ \\
\hline Mother's age (in year) & $-0.0134^{a}$ & 0.0071 & 0.045 & -0.0274 to -0.0002 \\
\hline \multicolumn{5}{|l|}{ Mother's educational level } \\
\hline \multicolumn{5}{|l|}{ Below high school (ref.) } \\
\hline High school and above & 0.1786 & 0.1116 & 0.110 & -0.0405 to 0.3978 \\
\hline \multicolumn{5}{|l|}{ Health insurance coverage } \\
\hline \multicolumn{5}{|l|}{ Yes (ref.) } \\
\hline No & -0.0810 & 0.1404 & 0.564 & -0.3567 to 0.1947 \\
\hline \multicolumn{5}{|l|}{ Sex of the child } \\
\hline \multicolumn{5}{|l|}{ Female (ref.) } \\
\hline Male & -0.1113 & 0.0905 & 0.219 & -0.2890 to 0.0664 \\
\hline \multicolumn{5}{|l|}{ Mother's birthplace } \\
\hline \multicolumn{5}{|l|}{ Rural (ref.) } \\
\hline Urban & 0.0483 & 0.1275 & 0.705 & -0.2021 to 0.2987 \\
\hline \multicolumn{5}{|c|}{ Monthly household income (in US\$) } \\
\hline \multicolumn{5}{|l|}{$<80$} \\
\hline $80-160$ & $0.3338^{\mathrm{a}}$ & 0.1342 & 0.013 & 0.0702 to 0.5974 \\
\hline $160-320$ & $0.5145^{\mathrm{a}}$ & 0.1488 & 0.001 & 0.2222 to 0.8068 \\
\hline$>320$ & $1.1013^{\mathrm{a}}$ & 0.2050 & 0.001 & 0.6987 to 1.5040 \\
\hline
\end{tabular}

Note: Dependent variable: logarithm WTP; number of observations: 667; F $(8,658): 8.12$; Prob>F:0.001; R-squared: 0.0716; S.E: standard error. ${ }^{\mathrm{a}}$ significant at $5 \%$ level 
mothers' educational status and birthplace, households' health insurance coverage, and the children's sex.

\section{Discussion}

This study uncovered mothers' WTA and WTP for vaccines to their children and associated factors. Eliciting the WTA and WTP for healthcare services such as immunization is a vital means of incorporating service users' preferences in health policy [22]. Besides, the disparity between the WTA and WTP is a useful means to illuminate not only the understanding of values attributed to particular services but also the need for service provision shift from public to private and the users' possible resistance due to the perceived loss of benefits from the public provider. The proportions of mothers that had the WTA and WTP for the vaccines in our study are considerably higher than the corresponding values reported for a hypothetical vaccine in Malaysia [23]. The WTA to WTP ratio is markedly lower than those reported for health and safety goods, public or non-market goods and even for the ordinary private goods in studies elsewhere. However, whether the elicitation method influenced the observed ratio value or not is not well understood [6].

The use of the WTA and WTP valuation approaches for an already received service can pose a debate. However, these measures are proven capable of providing insights concerning the disparity between the elicited values [2]. The mothers' mean WTA value of the vaccines in our study is about 1.6 times larger than their WTP. Similarly, others used the same measures of valuation of time, an ever-existing, equally distributed, and immediately consumed private non-market attribute, demonstrated about 1.5-2.0 times larger mean WTA value than the WTP measure [10]. Besides, the mean WTA for nursing consultation value was about 1.5 times larger than the mean WTP value [24].

Studies revealed the mean WTA to WTP ratio values greater than one for different services $[2,4]$, the mean ratio value (1.55 vs. 3.30$)$ less than the median ratio value, and several factors such as substitute attributes, incomplete information, the cost of goods, and uncertainty attributing to the disparity between these values [2]. The WTA and WTP values and their differences are also subject to the influences of type of vaccines, and disease severity. A vaccine for an acute disease with low mortality and morbidity is likely to have a lower mean WTP value than a chronic disease with high morbidity and mortality [25].

Our findings revealed a higher proportion of WTP and a lower proportion of unwilling mothers to pay for the vaccines to their children $(93.1 \%$ vs. $3.0 \%)$ than the corresponding values ( $88 \%$ vs. $55 \%$ ) reported from a study in Nigeria [26]. Besides, the mean WTP value in our study is lower than that reported for a hypothetical vaccine in Malaysia [27] and higher than the mean value (US\$2.08) reported for the Ebola vaccine elsewhere [28]. The WTP of mothers for the Human Papillomavirus vaccine to their daughters (US\$ 208) [29] was more than 48 times the mothers' mean WTP value (US\$ 4.3) for the vaccines to their children in our study. The discrepancy between WTA and WTP estimate can increase or decrease based on the perceived risk or benefit of a given attribute [30]. Thus, the possible lower perceived risk associated with the vaccines might have contributed to the lower mean WTP value observed in our study. Besides, the proportion of not WTP mothers (3.0\%) in our study is less than one-twelfth of the health professionals reported unwilling to pay for the Hepatitis B virus vaccine in Iran [31], and less than one-eighteenth of those (55\%) not WTP for influenza vaccine in China [32]. Generally, the fact that the immunization service is free of any payment might have contributed to the lower proportion of not willing to pay mothers for the vaccines to their children.

The findings of the regression analysis indicated a positive relationship between the mothers' WTP for vaccinating their children and the monthly income of the households. Both mothers' mean WTA and WTP values indicated statistically significant associations with the households' monthly income. The significant association between the mean WTP and household monthly income observed in our study may imply that the open-ended WTP questions are bounded by an individual's income [14]. Others also stated that the WTA and WTP are explained by income and substitution effects [10]. This finding implies that the wealthier respondents are likely to pay more money to avoid infectious diseases. Others also revealed a positive association of the participants' WTP for the hepatitis B vaccine with their income level [33]. Furthermore, for self-paid vaccination such as pneumonia and influenza vaccines, the individuals with the highest ability to pay had 18 times higher WTP value than those with the lowest ability to pay [32]. Others reported the monthly income as a key factor affecting the WTP [19]. However, the WTP values considerably vary with income, and the low- and middle-income countries had lower WTP compared to the high-income countries [25]. Besides income, mothers born in the urban areas, and being a female child showed statistically significant positive associations with the mothers' WTA for the vaccines. There was also a statistically significant negative relationship between mothers' age and the mothers' WTP. Others also found that a reduction in the maximum WTP for the self-paid vaccine as age increases [32].

\section{Limitations of the study}

Despite its contribution to the increased knowledge base on the WTA and WTP valuation for an attribute in 
healthcare and its role for policy action to improve the provision of the EPI services in Iran, our study has some limitations. First, the open-ended questions elicited WTA and WTP monetary values for the vaccines in our study are likely to be under- or overestimated. Second, the cross-sectional analysis does not allow to establish a causal relationship between the explained and explanatory variables. Finally, the study focused on mothers living in one metropolitan city of a province in Iran, and the findings cannot be generalizable to the entire Iran.

\section{Conclusion}

This study elicited evidence concerning mothers' WTA and WTP for vaccines to their 2 to 18 months old children in Kermanshah city, western Iran. The findings indicated a high proportion of mothers WTP for the vaccines to their children, and there existed statistically significant associations between the mothers' WTP, and households' monthly income, and the mothers' age. The mothers' mean WTA was also significantly associated with the households' income, children's sex, and mothers' birthplace. The mothers' WTA and WTP for the vaccines to their children observed in our findings contribute paramount importance input for policymakers to reinforce primary health care services including the expansion of EPI services in the private sector.

\section{Supplementary information}

Supplementary information accompanies this paper at https://doi.org/10. 1186/s12887-020-02208-4.

Additional file 1. Appendix 1: Current national childhood immunization program of Iran (May 2020).

Additional file 2. Participant Information Sheet and Informed Consent Form.

\section{Abbreviations}

CV: Contingent valuation; EPI: Expanded program on immunization; WTA: Willingness to accept; WTP: Willingness to pay

\section{Acknowledgements}

Not applicable.

\section{Authors' contributions}

All authors contributed to the conception and design of the study SR and BKM; and SR performed the data analysis. SR, MM and ShM collected the data and drafted the manuscript. AW critically revised the manuscript for important intellectual content. All authors read and approved the final manuscript.

\section{Funding}

This research received a grant from Kermanshah University of Medical Sciences (Grant number: 980427). However, the funder did not have any role in the design of the study, and in the collection, analysis, interpretation of data, and in the write-up of the manuscript.

\section{Availability of data and materials}

The data used for the analysis in this study are available from the corresponding author upon reasonable request.

\section{Ethics approval and consent to participate}

The ethics committee of the Deputy of Research, Kermanshah University of Medical Sciences, reviewed and approved reviewed the study protocol (IR.KUMS.REC.1398.517). Besides, the data were collected anonymously after obtaining informed verbal consent that approved by the ethics committee from each mother. The mothers were also explained about their rights of not participating, and withdrawing from the study at any point during the data collection process. The data were used only for this research objective.

Consent for publication

Not applicable.

\section{Competing interests}

The authors declare that they have no competing interests.

\section{Author details}

${ }^{1}$ Research Center for Environmental Determinants of Health, Health Institute, Kermanshah University of Medical Sciences, Kermanshah, Iran. ${ }^{2}$ Department of Health Systems, School of Public Health, College of Health Sciences, Mek'ele University, Mek'ele, Ethiopia. ${ }^{3}$ Student Research Committee, Kermanshah University of Medical Sciences, Kermanshah, Iran.

Received: 9 March 2020 Accepted: 16 June 2020

Published online: 23 June 2020

\section{References}

1. Porzsolt F, Ackermann M, Amelung $V$. The value of health care-a matter of discussion in Germany. BMC Health Serv Res. 2007;7(1):1.

2. Martín-Fernández J, del Cura-González Ml, Gómez-Gascón T, et al. Differences between willingness to pay and willingness to accept for visits by a family physician: a contingent valuation study. BMC Public Health. 2010;10(1):236.

3. Borghi J. Aggregation rules for cost-benefit analysis: a health economics perspective. Health Econ. 2008;17(7):863-75.

4. Grutters JP, Kessels AG, Dirksen CD, et al. Willingness to accept versus willingness to pay in a discrete choice experiment. Value Health. 2008;11(7): 1110-9.

5. Bayoumi AM. The measurement of contingent valuation for health economics. Pharmacoeconomics. 2004;22(11):691-700.

6. Horowitz JK, McConnell KE. A review of WTAMTP studies. Wtp studies, vol. 2000; 2000.

7. Ebert U. Approximating WTP and WTA for environmental goods from marginal willingness to pay functions. Ecol Econ. 2008;66(2-3):270-4.

8. Brebner S, Sonnemans J. Does the elicitation method impact the WTA/WTP disparity? J Behav Exp Econ. 2018;73:40-5.

9. Fehr D, Hakimov R, Kübler D. The willingness to pay-willingness to accept gap: a failed replication of Plott and Zeiler. Eur Econ Rev. 2015;78:120-8.

10. Ramjerdi F, Lindqvist DJ. Gap between willingness-to-pay (wtp) and willingness-to-accept (WTA) measures of value of travel time: evidence from Norway and Sweden. Transp Rev. 2007;27(5):637-51.

11. Yao-ji J, Qian Z, Cai-mei H. Assessment of the disparity between willingness to accept (WTA) and willingness to pay (WTP) by value. In: 2007 international conference on management science and engineering: IEEE; 2007.

12. Georgantzís N, Navarro-Martínez D. Understanding the WTA-WTP gap: attitudes, feelings, uncertainty and personality. J Econ Psychol. 2010;31(6): 895-907.

13. Biel A, Johansson-Stenman O, Nilsson A. The willingness to pay-willingness to accept gap revisited: the role of emotions and moral satisfaction. J Econ Psychol. 2011;32(6):908-17.

14. Whittington D, Adamowicz W, Lloyd-Smith P. Asking willingness-to-accept questions in stated preference surveys: a review and research agenda. Ann Rev Resour Econ. 2017;9:317-36.

15. Merkle $C$, Schreiber $P$, Weber M. Framing and retirement age: the gap between willingness-to-accept and willingness-to-pay. Econ Policy. 2017; 32(92):757-809.

16. Plott CR, Zeiler K. The willingness to pay-willingness to accept gap, the endowment effect, subject misconceptions, and experimental procedures for eliciting valuations. Am Econ Rev. 2005;95(3):530-45. 
17. Brown AL, Cohen G. Does anonymity affect the willingness to accept and willingness to pay gap? A generalization of Plott and Zeiler. Exp Econ. 2015; 18(2):173-84.

18. Moradi-Lakeh M, Esteghamati A. National Immunization Program in Iran: whys and why nots. Human Vaccines Immunother. 2013;9(1):112-4.

19. Javan-Noughabi J, Kavosi Z, Faramarzi A, et al. Identification determinant factors on willingness to pay for health services in Iran. Heal Econ Rev. 2017; 7(1):40.

20. Marra CA, Frighetto L, Goodfellow AF, et al. Willingness to pay to assess patient preferences for therapy in a Canadian setting. BMC Health Serv Res. 2005;5(1):43.

21. Liao D, Valliant R. Variance inflation factors in the analysis of complex survey data. Surv Methodol. 2012;38(1):53-62

22. Martín-Fernández J, Pérez-Rivas FJ, Gómez-Gascón T, et al. A study of the user's perception of economic value in nursing visits to primary care by the method of contingent valuation. BMC Fam Pract. 2011;12(1):109.

23. Yeo HY, Shafie AA. The acceptance and willingness to pay (WTP) for hypothetical dengue vaccine in Penang, Malaysia: a contingent valuation study. Cost Eff Resour Alloc. 2018;16(1):60.

24. Martín-Fernández J, del Cura-González Ml, Rodríguez-Martínez G, et al. Economic valuation of health care services in public health systems: a study about willingness to pay (WTP) for nursing consultations. PLoS One. 2013; 8(4):e62840.

25. Kim S-Y, Sagiraju H, Russell LB, et al. Willingness-to-pay for vaccines in lowand middle-income countries: a systematic review. Appl Health Econ Health Policy. 2014;1(1):1001.

26. Ughasoro MD, Esangbedo DO, Tagbo BN, et al. Acceptability and willingness-to-pay for a hypothetical Ebola virus vaccine in Nigeria. PLoS Negl Trop Dis. 2015;9(6):e0003838

27. Yeo H, Shafie A. How much do Malaysians value dengue vaccine? Evaluating the willingness to pay (WTP) for hypothetical dengue vaccine with two-part model (TPM). Value Health. 2018;21:56-7.

28. Mudatsir M, Anwar S, Fajar JK, et al. Willingness-to-pay for a hypothetical Ebola vaccine in Indonesia: a cross-sectional study in Aceh. F1000Research. 2019;8:1441

29. Wong $C K$, Man KK, Ip P, et al. Mothers' preferences and willingness to pay for human papillomavirus vaccination for their daughters: a discrete choice experiment in Hong Kong. Value Health. 2018;21(5):622-9.

30. Moon W, Balasubramanian SK, Rimal A. Willingness to pay (WTP) a premium for non-GM foods versus willingness to accept (WTA) a discount for GM foods. J Agric Resour Econ. 2007;1:363-82.

31. Abiye S, Yitayal M, Abere $G$, et al. Health professionals' acceptance and willingness to pay for hepatitis B virus vaccination in Gondar City Administration governmental health institutions, Northwest Ethiopia. BMC Health Serv Res. 2019;19(1):796.

32. Hou Z, Chang J, Yue D, et al. Determinants of willingness to pay for selfpaid vaccines in China. Vaccine. 2014;32(35):4471-7.

33. Sardar A, Yaseen MR, Abbas A, et al. Willingness to pay for vaccination against hepatitis $b$ and its determinants: the case study of an industrial district of Pakistan. Epidemiol Biostat Public Health. 2018;15:4.

\section{Publisher's Note}

Springer Nature remains neutral with regard to jurisdictional claims in published maps and institutional affiliations.

Ready to submit your research? Choose BMC and benefit from:

- fast, convenient online submission

- thorough peer review by experienced researchers in your field

- rapid publication on acceptance

- support for research data, including large and complex data types

- gold Open Access which fosters wider collaboration and increased citations

- maximum visibility for your research: over $100 \mathrm{M}$ website views per year

At $\mathrm{BMC}$, research is always in progress.

Learn more biomedcentral.com/submissions 